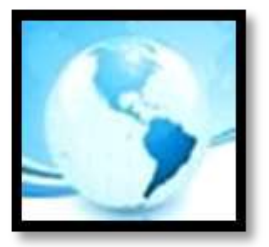

MALAYSIAN ONLINE JOURNAL OF

EDUCATIONAL MANAGEMENT

(MOJEM)

July 2020, VOLUME 8, ISSUE 3, 64-81

E-ISSN NO: $2289-4489$

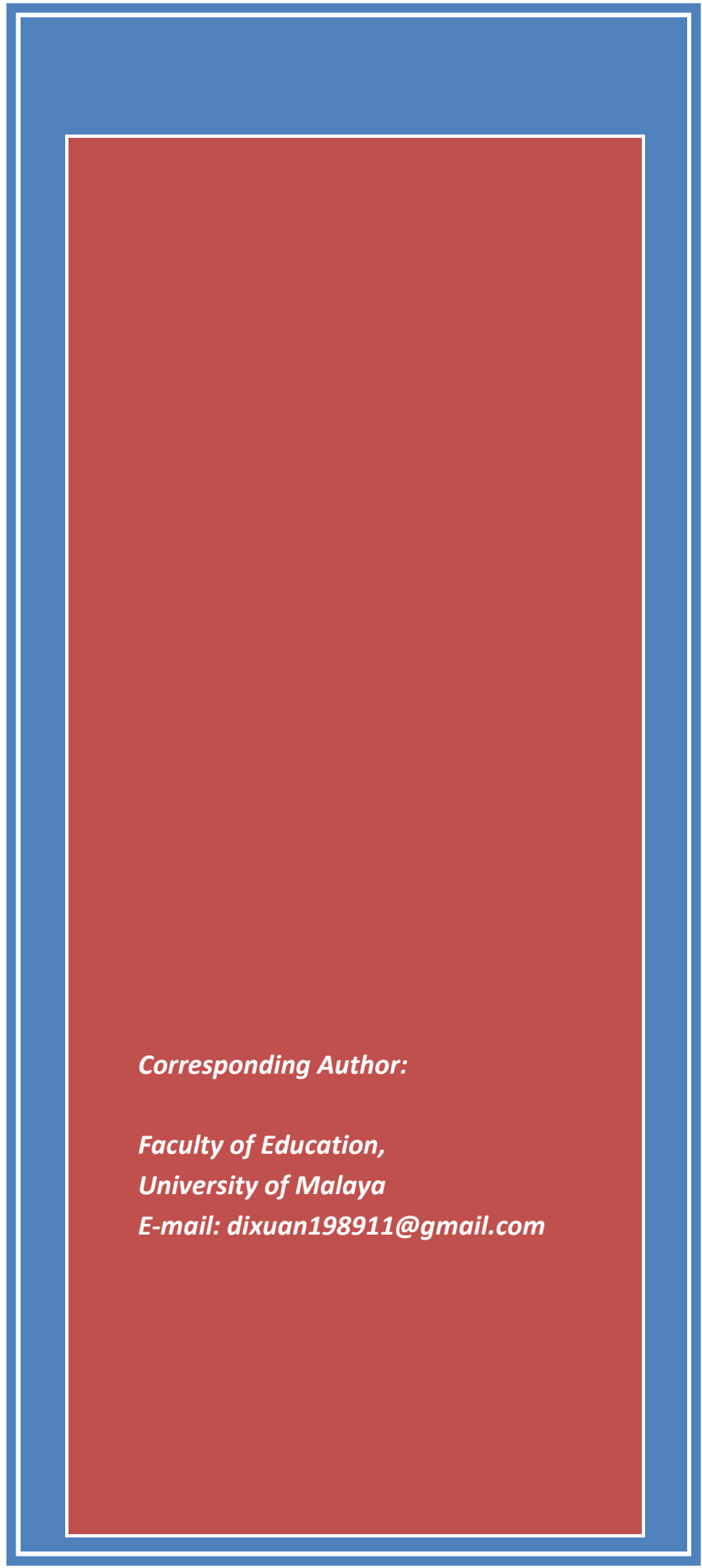

\title{
SELF-REGULATED LEARNING STRATEGIES AS ACADEMIC SELF-MANAGEMENT SKILLS IN MALAYSIAN PUBLIC UNIVERSITIES
}

Xuan Di, Muhammad Azhar Zailani (PhD), \& Wail Muin Ismail (PhD)

\begin{abstract}
It is evident that academic self-management is one of the skills which predict and improve students' academic outcomes. The present study investigated students' academic self-management skills (ASMS) by studying their self-regulated learning strategies (SRLS) and explored whether SRLs predict students' academic performance, as well as gender and year of study differs in SRLs among undergraduate students in Malaysia. The study was conducted with a quantitative survey methodology by distributing a questionnaire to six public universities in Malaysia. A total of 317 university undergraduate students participated in the current study of self-regulated online learning questionnaire (SOL-Q). Hypothesis testing was done by using inferential analysis in SPSS Version 22. Quantitative data analysis showed that students have a medium level of SRLs. The results varied based on the study years of the students in SRLs, but, not on their gender. The metacognitive skills are found influential on students' academic outcomes (GPA). The study has reflected the need to enhance students' SRLs to develop 21st-century skills for life-long learning. The implications of the results for language learning and educational practices may be suitable for students and instructors of the faculty.
\end{abstract}

Keywords: Academic Self-Management Skills, Academic Performance, Language Learning 


\section{INTRODUCTION}

Today, life-long learning is becoming increasingly important in society. The goal of education is no longer just for obtaining a paper qualification, but it is about developing students' skills to be better prepared for the 21st century and whatever job they may undertook afterwards. Students are expected to fully develop their optimal potential during their academic life. Learners are required to master self-management or self-regulating skills (Dabbagh \& Kitsantas, 2012; Tu, Yen, \& Sujo-Montes, 2015). Academic self-management is defined as powers of students adapted for effective study toward long-term and short-term learning goals, manage times for assigning tasks, and to be flexible toward attaining meaningful academic outcomes (Kadiyono, Anissa, \& Hafiar, 2017). The process of SRL involves managing self-learning (Gravill \& Compeau, 2008). Kadiyono and Hafiar (2017) found that academic self-management was one of the skills which predict and improve academic achievement. According to Zimmerman and Campillo (2003) proposed the self-regulated learning (SRL) includes performance, forethought, and self-reflection. As presented in Figure 1, in the forethought phase, the learner analyses the task first, then, sets target goals, plans strategies to use, manage time, and a series of self-motivation settings. Subsequently, during the performance, control and observation of oneself are essential to managing performance. Lastly, the selfreflection phase involves feedback analysis is whereby learners self-judge and self-evaluate the task outcomes and themselves to summarize the experience. Drucker (2005) stated feedback analysis as a core element of selfmanagement. Thereby, these circle processes called learners SRL process, as well as, procedures of SM. As demonstrated in Figure 1, self-management processes were displayed in general, and the SRL process were shown in detail.

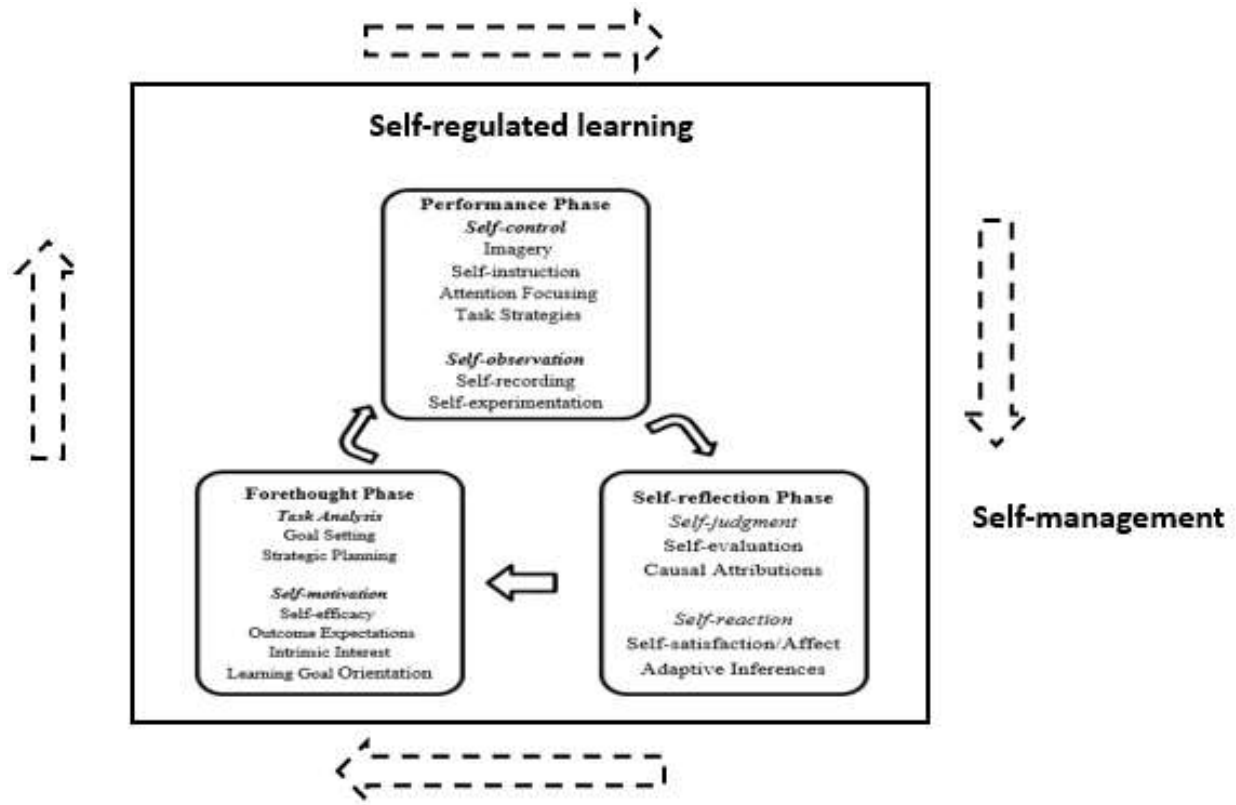

Figure 1. Procedure of SRL and SM

SRL is typically grounded in social cognitive theory (SCT). As defined by Pintrich (2004), it is a positive process in which learners set objectives for the target task and then try to manage time, regulate and control their cognition, motivation, and behaviour, which will encourage persistence when restricted by their goals and environmental contexts. Hence, it is essential for fostering student self-regulation in learning. Forgas, Baumeister, and Tice (2011) defined SRL as to confirm with the idea or concept to change oneself or some aspect of oneself. More recently, self-regulation is one's ability to manage energy states, emotions, behaviour, as well as attention to help achieve positive goals in a socially recognized way, such as maintaining good relationships, learning, and maintaining wellbeing. 


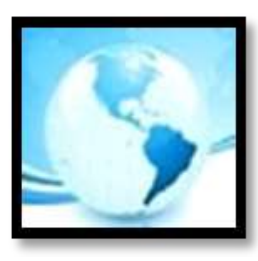

\section{MALAYSIAN ONLINE JOURNAL OF EDUCATIONAL MANAGEMENT (MOJEM)}

Recently, as the use of technology is increasing in learning, SRL and technology use form a "natural alliance" at a pedagogical level for both formal and informal education among college university students (Dabbagh \& Kitsantas, 2012; Matzat \& Vrieling, 2016; Tu et al., 2015) self-regulated learning has become extremely valuable in developing 21st-century skills for students (Google \& Canvas8, 2019).

Besides, Pintrich (1995) stated why SRL is indispensable for college students and faculty. One reason is that SRL offers a promising perspective on college learning and teaching due to various presumptions about learning and teaching, a) Self-regulation is not born but acquired, b) SRL is controllable, c) SRL is fit for the college university context, d) SRL is teachable, e) SRL assists technology using at the pedagogical level, (Dabbagh \& Kitsantas, 2012; Tu et al., 2015; Matzat \& Vrieling, 2016; Google \& Canvas8, 2019). Figure 2 illustrates the presumptions behind SLR.

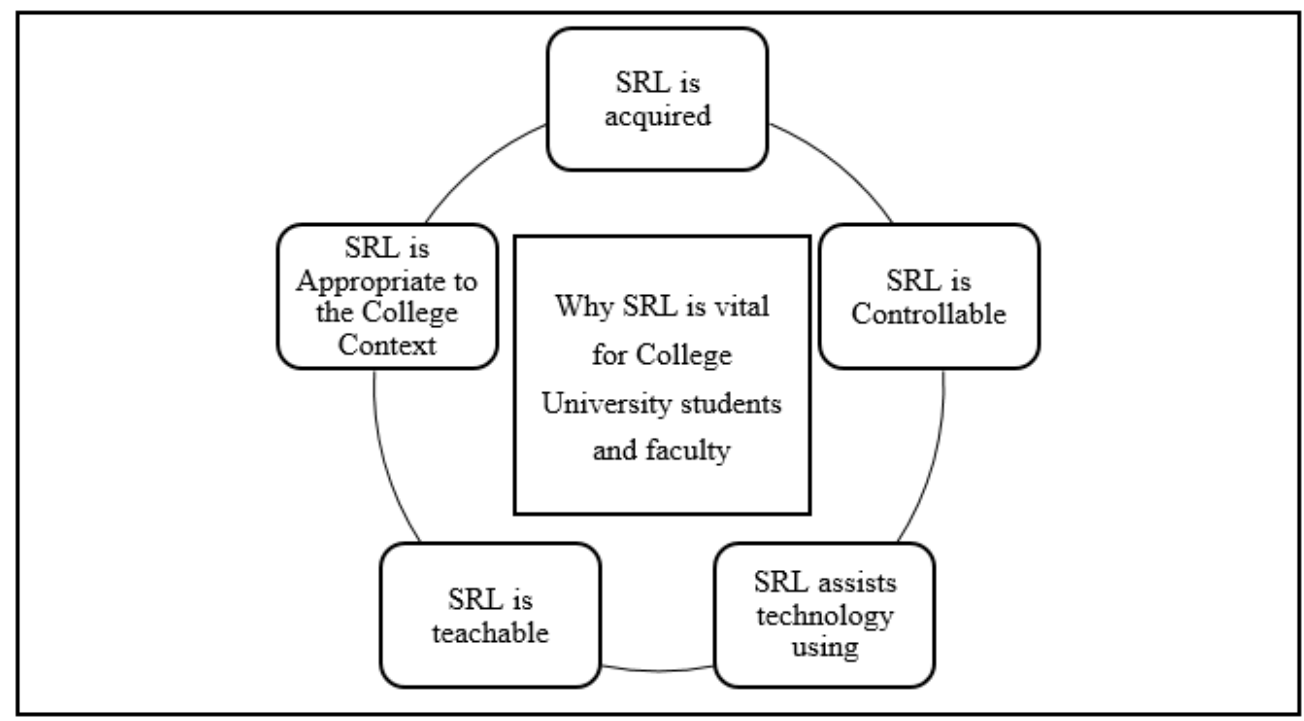

Figure 2. Why SRL vital for College University students and faculty (Dabbagh \& Kitsantas, 2012; Matzat \& Vrieling, 2016; Pintrich, 1995; Tu et al., 2015)

Besides, Jansen et al. (2017) summarized SRLs with five core strategies in his study as:

a) Metacognitive skills: Metacognitive skills play a vital role in a variety of cognitive activities, including information exchange, good reading comprehension, motivation, language understanding, writing, language learning, perception, attention, memory, problem-solving, and social cognition (Brown, 1987). As Flavell (1979) explains, "...metacognitive knowledge can lead you to select, evaluate, revise, and abandon cognitive tasks, goals, and strategies in light of their relationships with one another and with your abilities and interests concerning that enterprise." Metacognition is one's awareness of his/her own ability to think and regulate, control, and manipulate the thinking process. Metacognitive strategies (MS), on the other hand, refers to the skill of using previous knowledge to plan a strategy for a specific learning task, take necessary steps to solve a problem, reflect on and evaluate results, and modify one's strategy as needed. b) Help-seeking: Ryan, Pintrich, and Midgley (2001) stated that help-seeking was an SRL Strategy (SRLS), which was used by the students to face academic challenges. It was used as a tool to acquire the necessary help. Academic HS was seen to be a vital learning technique because the learners who experienced a learning impasse and showed a less satisfactory performance could require guidance and assistance so that they could continue their learning process. In such situations, it is essential to calibrate the extent of the learner's need for help. The students need to identify all their issues, determine if they require assistance, decide if they wish to seek help and determine what type of help (i.e., instrumental or executive), whom to ask for assistance and finally understand the help that they have received (Karabenick \& Dembo, 2011). HS was considered as an integrated learning technique instead of a degrading activity, which must be avoided 


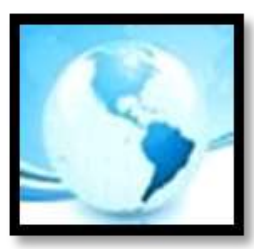

\section{MALAYSIAN ONLINE JOURNAL OF EDUCATIONAL MANAGEMENT (MOJEM)}

(Black \& Allen 2019). As Karabenick and Berger (2013) reported, "The process of seeking assistance from other individuals or other sources that facilitate accomplishing desired goals, which is an academic context may consist of completing assignments or satisfactory test Performance". (P-238) In some of the earlier reports (Newman, 2000; Karabenick, 2004), the researchers argued that the university students could monitor and evaluate their success and determine if they needed any additional assistance with regards to their academic curriculum. However, they stated that majority of the student shy away from actively seeking support and help with their studies (Newman, 2000; Karabenick, 2004). c) Persistence: Persistence is another expression of motivation. It is this quality that enables one to continue to do something for a long period without interruption despite the challenges. It is the quality that allows someone to continue in pursuit of a goal even when challenges arise. A student must want to persist to degree completion to expend considerable effort to do so (Tinto, 2017). d) Environmental structuring: Statements indicating student-initiated efforts to select or arrange the physical setting to make learning easier. Samani and Samani (2012) good environmental designing in schools and universities is a kind of stimulus for students and even teachers to have better performance. e) Time management: The analysis of how the working hours are spent and the prioritization of tasks to maximize personal efficiency in the target task. Time management is the skill of arranging, organizing, scheduling, and budgeting one's time for generating more effective work and productivity. Khanam, Sahu, Rao, Kar, and Quazi (2017) as well as Ganguly, Kulkarni, and Gupta (2017) suggested that time management could be one of the strategies that might help students to cope with stress and stress-related outcomes. The previous study by Pozdeeva (2019) convincingly demonstrated that time management strategy is increasable, however, it is not clear to what extent it is possible to influence the academic outcomes through TM.

\section{LITERATURE REVIEW}

Past empirical studies by Zimmerman and Martinez-Pons (1986) first proved SRLs were shown to be significantly effective for the academic system. Then, Zimmerman and Martinez-Pons (1988) presented that there the ratings provided by teachers with the reports corresponding to the ones given by students of their SRLs use. Among them, the SRLs of practicing, managing, and revision of tests were the ones that correlated the most with the teachers' ratings. It implies that good SR learners use SRLs effectively for better achievement in their classroom activities. Andrade and Bunker (2009) showed that implementing these regulations influence course design and, therefore, learner performance.

Abbasnasab (2012) investigated SRL and FLL (Foreign Language Learning) among Iranian learners. The results also showed that SRL positively predicted students' language learning, and female students performed better in both academic performance and SRLs use than male students. Subsequently, Ibrahim et al. (2015) reported a significant correlation between SRL and CGPA coupled with moderate interaction effect of SRL with the Qur'an on academic achievement. Seker (2016) discovered the potential and significance of SRL research for the foreign language teaching discipline in stimulating and supporting SRL implementation in language instruction. Moreover, Haron, Ahmad, Mamat, and Mohamed (2010) reported in their study that the good Arabic speakers are more frequently apply self-regulated learning strategies.

Kosnin (2007) investigated students' self-regulated learning and applied Motivated Strategies for Learning Questionnaires (MSLQ) to predict academic achievement among undergraduates in Malaysia. A total of 460 second-year engineering undergraduates from Universiti Teknologi Malaysia participated in the study. The results showed that SRL is a significant predictor of Malaysian undergraduates' academic achievement.

Yusri (2010) studied self-regulated learning strategies in learning Arabic among 98 students at Universiti Teknologi MARA (UiTM), Malaysia. The findings explored students with a medium level of self-regulated learning strategies usage, and the dimensions of SRLs such as, metacognitive skills, time management are at a moderate level as well, unlike the help-seeking strategy which was shown in the high level of usage among students. This study also found that gender and study experiences are not factors that can predict their SRLs. Likewise, Xuan et al. (2020) stated a 


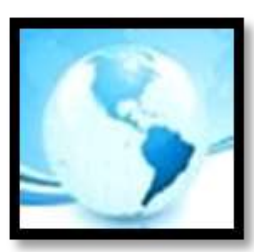

\section{MALAYSIAN ONLINE JOURNAL OF EDUCATIONAL MANAGEMENT (MOJEM)}

high frequency of help-seeking strategy usage among Arabic learners in Malaysian public universities. In turn, study experience is a significant predictor help-seeking strategy.

In contrast, some studies indicated no correlation between SRL and academic performance for second language learning; Mahmoodi, Kalantari, and Ghaslani (2014) studied self-regulated learning (SRL) and L2 and this study found no significant relationship between SRL and L2 achievement. The relationship between SRL and achievement was also discussed by Ablard and Lipschultz (1998), wherein they suggested that high-level achievement does not necessarily mean that SRLs will be more widely used. Gender differences have also been noted, suggesting that girls use more self-regulation strategies than boys do. In addition to that, Garavalia, Scheuer, and Carroll (2002) compared the first-and third-year pharmacy students' perceptions of student-regulated learning strategies, and the results revealed that year one students to have greater SRLs than their senior counterparts.

Indeed, personal aspirations are critical in fostering interest in the study of knowledge, the inspirational credence, and effective use of cognitive expertise in the SRL field. However, these attributes are implemented based on disciplines and conceptualization of self-regulation. The features of thought-out efforts and SRL vary significantly as presented by different courses. Hence, it is essential for university educators to explore further how to improve students' skills of using SRLs and assist students to achieve learning ability by self-regulation, during university studies as well as in long-term goals of life-long learning. Also, Oxford (1999) recommended for future studies understanding the role of gender in SRL. The past empirical study above had indicated, the various roles of gender and study experience are played in SRLs. Several researchers mentioned that male and female students demonstrated differences in using SRLs in their learning (Ablard \& Lipschultz, 1998; Zimermann \& Martinez-Pons, 1986; Abbasnasab, 2012), some were not (Yusri, 2010; Yusri, Rahimi, \& Wah, 2011; 2013; Xuan et al., 2020). And some more (Xuan, Azhar, \& Muin Ismail, 2020) reported study experience was significantly predict SRLs. In addition to that, Garavalia et al. (2002) compared the first-and third-year pharmacy students' perceptions of studentregulated learning strategies, and they found year one students with greater SRLs than their senior counterparts.

The previous studies reported that many students find that it's hard to find a balance between their studies and daily lives (Adams \& Blair, 2019). As reported by Khanam et al. (2017), a vast majority of university students complain about the shortage of time to do target task, in turn, some other students got sufficient time to complete their assignments with no struggle due to the diversity of their learning time and the quality of the cognitive effort invested. King-Sears (2006) referred to Self-management plans that are used to teach students to complete tasks and take an active role in monitoring and reinforcing their behaviour. A report by Zimmerman, Greenberg, and Weinstein (1994) states that if students can control their study schedules and academic activities, they will be better able to meet academic needs and be able to balance college life with extracurricular activities. In this regard, necessary to investigate research on SRL as Academic Self-Management skills among university students and find out that it relates to their performance.

Therefore, this paper investigates the self-regulated behaviour of university students of Arabic, and the related achievement, aimed at a better understanding of how their SRL strategies relate to academic performance and gender.

\section{Research Questions}

1. What is the level of students' self-regulated learning strategies?

2. Are there any statistically significant differences in self-regulated learning strategies based on their gender?

3. Are there any statistically significant differences in self-regulated learning strategies based on their years of study?

4. Are there any statistically significant influence of self-regulated learning strategies in Academic Performance? 


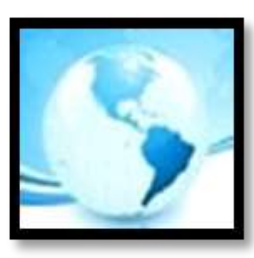

\section{Hypotheses of The Study}

$\mathrm{H}_{1}$ : There are statistically significant differences in self-regulated learning strategies based on their gender.

$\mathrm{H}_{2}$ : There are statistically significant differences in self-regulated learning strategies based on their years of study.

$\mathrm{H}_{3}$ : There are significant influences of self-regulated learning strategies in academic achievement.

\section{METHODS}

\section{Research Design}

The study was conducted with a quantitative survey methodology by distributing a questionnaire to six public universities in Malaysia. A total of 317 university undergraduate students participated in the current study by employing Jansen et al. (2017)'s self-regulated online learning questionnaire (SOL-Q). Hypothesis testing was done by using inferential analysis in SPSS Version 22.

\section{Participants}

The population of this study consisted of around 1744 Malay bachelor degree Arabic learners (Year one, Year 2, Year 3 and Year 4) in faculty of Arabic language as the second language, or Islamic study from six universities which are University of Malaya (UM), University Kebangsaan Malaysia (UKM), International Islamic University Malaysia (IIUM), Universiti Sultan Zainal Abidin (UniSZA), Universiti Putra Malaysia (UPM) and Universiti Sains Islam Malaysia (USIM). As referred to Krejcie and Morgan's sample size table, the minimum number of respondents needed for this study at a 95\% confidence level is 317 students. As displayed in Table 1, regarding demographic information, the gender of participants comprised $14.2 \%$ male and $85.8 \%$ female. Most participants were attending university in their second year $(50.9 \%)$, first-year $(21.7 \%)$, third year $(11.8 \%)$ or fourth year $(15.6 \%)$. In terms of previous GPA, 188 out of 317 respondents (59.4\%) achieved B grade. A total of $34.9 \%$ of respondents $(n=111)$ achieved an $A$ grade, and for the rest, $5.7 \%(n=18)$ achieved $C$ for their grade. The profiles of the respondents, according to the demographic characteristics, are displayed in Table 1.

Table 1

Respondent Profile According to Demographic Characteristics ( $N=317)$

\begin{tabular}{llll}
\hline Variables & Characteristics & Frequency & Percent (\%) \\
\hline Gender & Male & 45 & 14.2 \\
Year of study & Female & 272 & 85.8 \\
& Year one & 69 & 21.7 \\
& Year two & 161 & 50.9 \\
& Year three & 38 & 11.8 \\
GPA & Year four & 49 & 15.6 \\
& A & 111 & 34.9 \\
& B & 188 & 59.4 \\
\hline
\end{tabular}

\section{Instruments}

The questionnaire developed as the survey instrument of this study consists of three sections. Section A included the participants' demographics and personal information related to the study. This section comprises three questions regarding the participants' demographic information, which were (1) learner's gender, (2) learner's level of study (3) learner's academic achievement. Section B measured the learners' SRLs in which a further instrument was needed. Jansen et al. (2017) the online learning questionnaire (SOL-Q) was used to measure SRLs among 


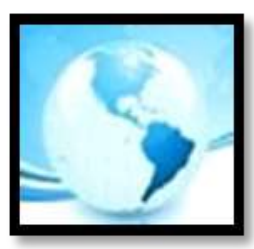

\section{MALAYSIAN ONLINE JOURNAL OF EDUCATIONAL MANAGEMENT (MOJEM)}

Arabic learners in this section for some reason. Indeed, there are several questionnaires are available to measure SRLs. These include the Motivated Strategies for Learning Questionnaire (Pintrich, 1991) which was the most widely cited one by SRL studies (Duncan \& McKeachie 2005), MSLQ is a measure developed by Pintrich and his colleagues. The MSLQ is a self-report instrument used by students to rate themselves on various cognitive and motivational items. Also, the MSLQ which includes a range of scales from the performance phase but does not measure self-regulatory behaviour in the preparatory and appraisal phases. More than that, there is also the Metacognitive Awareness Inventory (MAI) by Schraw and Dennison (1994), the Learning Strategies Questionnaire (LS) by Warr and Downing (2000), and the self-regulated online learning questionnaire (Jansen et al., 2017). After comparing existing questionnaires, none of them exactly fit the current study except the self-regulated online learning questionnaire (SOL-Q) by Jansen et al. (2017) who developed it with deliberate process and has been validated in the context of MOOCs. As the present study is a case to investigate SRLs among learners in the context of Arabic learning, this questionnaire has been chosen to apply SOL-Q rather than the others in this study.

On the other hand, as most participants learning the Arabic language were Malaysian, the researcher found that some did not understand English very well. Therefore, the questionnaire items used the Malay language to avoid errors relating to the participants' comprehension of the questions and task at hand. In the Procedure of Questionnaire Translation, three different sets of people involved in produce the final version of the translated questionnaire in the current study: translators, translation reviewers, and the last translation adjudicators. Firstly, the researcher selected two Malaysian translators as the main translator for the instrument from the English version to the Malay (Bahasa) version. Second, the researcher sent the readied questionnaire to the two reviewers, one of them is a Malay language teacher in Islamic Adni school and the other is Research Fellow / Senior Lecturer in UKM. The reviewers modified in some items as shown in Appendix A. Lastly, the researcher handed the final edit questionnaire to adjudicators, both are Malaysian and Senior Lecturer in the University of Malaya. The adjudicators gave some advice and decided to use it for this study.

\section{Pilot study}

A pilot study was undertaken involving 35 students which did not require further review or modification of the survey instrument. The correlation coefficient $(r)$ is a measure of the direction and strength of the relationship between variables (Chua, 2013). The reliability of the questionnaire showed that the Cronbach's alpha for the SRLS dimensions was in the range between 0.611 and 0.921 . As the value of $r$ showed in Table $2,0.611$ was considered moderate reliability between variables (Chua, 2013). These demonstrated a good level relating to internal consistency and reliability. Therefore, the questionnaire can apply to the current study.

Table 2

The Strengths of Correlation Coefficient Values

\begin{tabular}{ll}
\hline Correlation Coefficient $(r)$ & Strength of Correlation \\
\hline .91 to 1.00 or -.91 to -1.00 & Very Strong \\
.71 to .90 or -.71 to -.90 & Strong \\
.51 to .70 or -.51 to -.70 & Average/ Moderate \\
.31 to .50 or -.31 to -.50 & Weak \\
.01 to .30 or -.01 to -.30 & Very Weak \\
.00 & No Correlation \\
\hline
\end{tabular}

\section{Distribution and Collection of Questionnaires}

The instruments distribution and collection were from 6 universities: University of Malaya (UM), International Islamic University Malaysia (IIUM or UIA), The National University of Malaysia (UKM) in Malaysia, Universiti Sultan Zainal Abidin (UniSZA), Universiti Putra Malaysia (UPM), and Universiti Sains Islam Malaysia (USIM). In the 


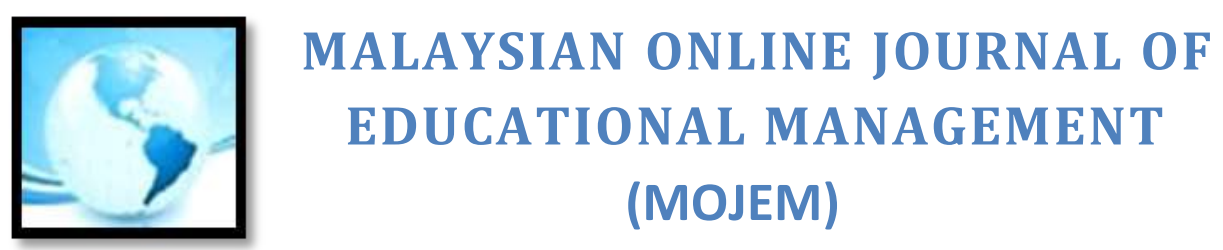

beginning, the researcher prepared approval letters, timetables, lecturer's contact numbers from the three sample universities Arabic language learning department to distribute the questionnaire to Malay Arabic learners. Then, the researcher discussed with the staff about the methods distribution in the following:

First, the researcher received permission from the lecturers to attend classes in order to distribute the questionnaires. The questionnaire was then collected the next day in the same class. The researcher stated that if the students forgot to return the questionnaire, they were asked to send pictures of the answered questionnaire via WhatsApp or Email. Second, the researcher received permission from the lecturers to send online questionnaires via the method of Google Form to the participants involved. The researcher asked for the participants' contact number and E-mail which was then used to send the online questionnaires to. Once the participants have finished with the questionnaire, they just submit it online without any fuss. The participants were given ample time to finished the questionnaire and were encouraged to ask questions in they did not understand any items in the questionnaire alongside receiving an appreciation gift by the researchers for completing the questionnaire.

\section{Data Analysis}

This study's data was analysed using SPSS version 22 software. Both descriptive and inferential statistics were used to analyse the data and to examine the relationship among learners' SRLs and GPA. The data and analysis of SRL was supported by using a 5-point Likert scale. Three different statistical analysis procedures were used to assess participant responses. The research questions were initially analysed using descriptive statistics to determine the mean and standard deviation, and later inferential statistics to determine the influence of SRLs on academic outcomes (GPA).

\section{RESULTS}

\section{The Level of SRLS}

The descriptive data mean and standard deviation for the dimension of Arabic learners' SRL were reported, as shown in Table 3:

Table 3

Mean and Std. Deviation of using SRL

\begin{tabular}{lll}
\hline Dimensions SRLS & Mean & $S D$ \\
\hline MS & 3.92 & .49 \\
ES & 3.58 & .52 \\
TM & 2.72 & .86 \\
Persistence & 3.88 & .70 \\
HS & 4.12 & .52 \\
Total SRLs & 3.65 & .39 \\
\hline
\end{tabular}

The descriptive statistics, as shown in Table 3, depicted that the overall mean of Arabic learners using SRLs for Arabic learning is 3.65. This could be interpreted as a medium degree of usage for SRLs among Arabic learners. In other words, Malaysian university Arabic learners had a medium level of SRLs usage. Furthermore, help-seeking is shown as the most common strategy used by Arabic learners $(M=4.12, S D=.38$ ) which could be interpreted as a high level of usage. In other words, Arabic learners in Malaysia are quite good in help-seeking strategies (HS), whether from lectures, the library, or the internet. Metacognitive skills (MS) as the second strategy are frequently used by Arabic learners depicted $(M=3.92, S D=.485)$, which is also a popular strategy applied by Arabic learners, also displaying a high level of usage. However, time management strategy as the lowest depicted $(M=2.72, S D=$ 


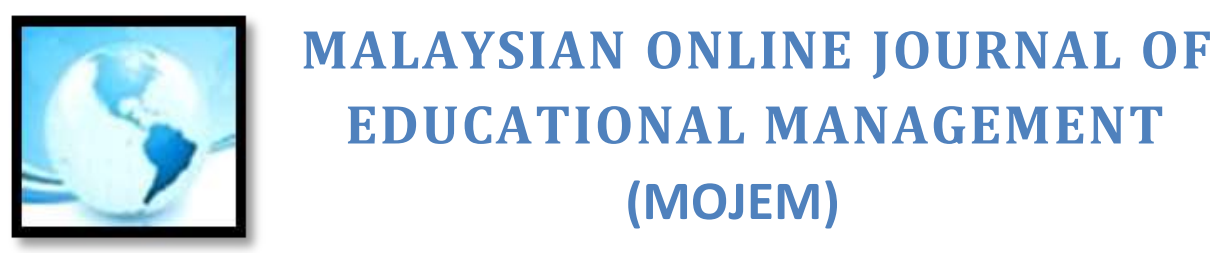

.857) with low degree of usage compared with the persistence strategy $(M=3.88, S D=.70)$ and the environmental structuring strategy $(E S)(M=3.58, S D=.519)$. In other words, Arabic learners used persistence and environmental structuring strategies more frequently compared to time management strategies.

\section{Test of Hypothesis 1}

$\mathrm{H}_{1}$ : There are statistically significant differences in self-regulated learning strategies based on their gender.

The normality test based on Gender for each of the dimensions SRLs were conducted through SPSS and reported in the following Table 4.

Table 4

Value of the Normality Z-value for SRLs differ in Gender

\begin{tabular}{llll}
\hline Variables & Gender & Skewness (Z) & Kurtosis (Z) \\
\hline MS & Male & -.319 & 2.099 \\
& Female & -.131 & .917 \\
ES & Male & .263 & .322 \\
& Female & .421 & .209 \\
TM & Male & .549 & .105 \\
Persistence & Female & .345 & .068 \\
& Male & -.600 & 1.746 \\
HS & Female & -.699 & 1.138 \\
& Male & -.884 & 2.708 \\
\hline
\end{tabular}

Table 4 indicated that the data male and female responders' SRLs are typically normally distributed (as shown by skewness and kurtosis values) which is in the range of -2 to +2 (Chua, 2013). Besides, the kurtosis value for male MS and HS was 2.099 and 2.708 respectively, which exceed +2 . Therefore, the value of the Normality Z-value suggested all the variables are normally distributed approximately. In other words, these data are different from non-parametric. And parametric tests independent sample $t$-test should be applied to analyse the data in this case.

Table 5

Independent Sample T-test in Gender difference

\begin{tabular}{|c|c|c|c|c|c|c|}
\hline & \multicolumn{2}{|c|}{ Levene's Test of Variances } & \multicolumn{4}{|c|}{ t-test for Equality of Means } \\
\hline & $F$ & Sig. & $t$ & df & Sig. & Mean Difference \\
\hline \multirow{2}{*}{ MS } & .001 & .976 & .742 & 301 & .459 & .05783 \\
\hline & & & .725 & 77.799 & .471 & .05783 \\
\hline \multirow{2}{*}{ ES } & .325 & .569 & .544 & 315 & .587 & .04127 \\
\hline & & & .525 & 77.486 & .601 & .04127 \\
\hline \multirow{2}{*}{ TM } & 1.004 & .317 & .962 & 313 & .337 & .11873 \\
\hline & & & .880 & 74.043 & .382 & .11873 \\
\hline \multirow{2}{*}{$P$} & .009 & .923 & -.754 & 308 & .451 & -.08052 \\
\hline & & & -.762 & 81.933 & .448 & -.08052 \\
\hline \multirow{2}{*}{ HS } & .378 & .539 & 1.064 & 315 & .288 & .08401 \\
\hline & & & 1.016 & 76.779 & .313 & .08401 \\
\hline
\end{tabular}

As shown in Table 5, an Independent Sample $t$-test was conducted to determine whether there was a difference in SRLs between male and female Arabic learners. Results of that analysis indicated that SRL usage was not significantly different between male and female Arabic learners in each of the dimensions SRLs, namely, MS, ES, 


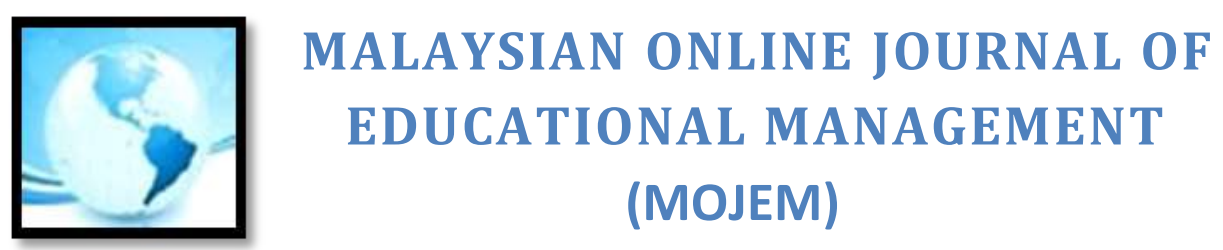

TM, Persistence, and HS as $p>.05$. Therefore, the male and female Arabic learners exhibited the same degree of MS, ES, TM, Persistence, and HS strategies use. This indicated that male and female Arabic learners with the same degree of SRLs agreement. In other words, there is no such difference between males and females in SRLs usage in Arabic learning. Thus, $\mathrm{H}_{1}$ was rejected.

\section{Test of Hypothesis 2}

$\mathrm{H}_{2}$ : There are statistically significant differences in self-regulated learning strategies based on their years of study.

Table 6

Value of the Normality Z-value for SRLs in Year of study difference

\begin{tabular}{llll}
\hline & Year of Study & Skewness & Kurtosis \\
\hline MS & Year one & .611 & -.931 \\
& Year two & .069 & .827 \\
& Year three & -.941 & 1.084 \\
& Year four & -.155 & 1.897 \\
& Year one & .689 & -.151 \\
& Year two & .303 & .325 \\
& Year three & -112 & -1.087 \\
TM & Year four & -.112 & -.210 \\
& Year one & -.239 & .341 \\
& Year two & .341 & -.447 \\
& Year three & .285 & .044 \\
& Year four & .611 \\
& Year one & .244 & -.781 \\
& Year two & .710 & 1.991 \\
& Year three & -.258 & 1.323 \\
& Year four & -.870 & 1.161 \\
& Year one & -1.220 & -.056 \\
& Year two & -.754 & .077 \\
& Year three & .204 & 1.735 \\
& Year four & .200 & -1.202 \\
\hline
\end{tabular}

Table 6 indicated that the data Year One, Year Two, Year Three, and Year Four responders' SRLs are typically normally distributed (as shown by skewness and kurtosis values) which is in the range of -2 to +2 (Chua, 2013). As well as, the kurtosis value for Year One, Year Two, Year Three, and Year Four responders, which in the range of -2 to +2 . Therefore, the value of the Normality Z-value suggested all the variables are normally distributed. In other words, these data are different from non-parametric. Parametric tests ANOVA should be applied to analyse the data in this case.

Table 7

One-way ANOVA Test

\begin{tabular}{lllllll}
\hline & & Sum of Squares & $\mathrm{df}$ & Mean Square & $\mathrm{F}$ & Sig. \\
\hline MS & Between Groups & 6.959 & 3 & 2.320 & 9.189 & .000 \\
& Within Groups & 75.478 & 299 & .252 & & \\
ES & Total & 82.437 & 302 & & 3.298 & .021 \\
& Between Groups & 2.561 & 3 & .854 & .259 & \\
& Within Groups & 81.023 & 313 & & \\
& Total & 83.585 & 316 & & & \\
\hline
\end{tabular}




\begin{tabular}{|c|c|c|c|c|c|c|}
\hline & \multirow{4}{*}{$\begin{array}{l}\text { Between Groups } \\
\text { Within Groups } \\
\text { Total }\end{array}$} & \multicolumn{4}{|c|}{$\begin{array}{l}\text { ALAYSIAN ONLINE JOURNAL OF } \\
\text { EDUCATIONAL MANAGEMENT } \\
\text { (MOJEM) }\end{array}$} & \multirow{4}{*}{.016} \\
\hline & & 7.206 & 3 & 2.402 & 3.511 & \\
\hline \multirow{2}{*}{ TM } & & 212.765 & 311 & .684 & & \\
\hline & & 219.971 & 314 & & & \\
\hline \multirow[t]{3}{*}{$P$} & Between Groups & 9.271 & 3 & 3.090 & 6.222 & .000 \\
\hline & Within Groups & 151.993 & 306 & .497 & & \\
\hline & Total & 161.265 & 309 & & & \\
\hline \multirow[t]{3}{*}{ HS } & Between Groups & 2.531 & 3 & .844 & 2.992 & .031 \\
\hline & Within Groups & 88.266 & 313 & .282 & & \\
\hline & Total & 90.797 & 316 & & & \\
\hline \multirow[t]{3}{*}{ URL } & Between Groups & 5.128 & 3 & 1.709 & 11.357 & .000 \\
\hline & Within Groups & 43.647 & 290 & .151 & & \\
\hline & Total & 48.775 & 293 & & & \\
\hline
\end{tabular}

Table 7 shows the results of a one-way ANOVA test that was conducted to compare the differences in MS, ES, TM, Persistent, HS, as well as the overall self-regulated learning strategies (SRLs) in different years of study. There was a significant difference between years of study in SRLs in general $(F(3,290)=11.357, p=.000)$. A Tukey post hoc test displayed in Table 8 shows that the Year One group was significantly greater statistically in SRLs than the Year Two, Year Three and Year Four learners $(p=.000)$. Subsequently, the Year Four learners scored the second highest, while the Year Three learners scored the lowest in SRLS.

By the same token, there was a significant difference between years of study in $\operatorname{MS}(F(3,299)=9.189, p=.000)$. A Tukey post hoc test displayed in Appendix A shows that the Year One group was significantly greater statistically in MS than the Year Two, Year Three and Year Four learners $(p=.000)$. Subsequently, the Year Four learners scored the second highest while the Year Two learners scored the lowest in MS. Moreover, there was a significant difference between the years of study as well for $\operatorname{ES}(F(3,313)=3.298, p=.021)$, Persistent $(F(3,306)=6.222, p=$ $.000)$, and HS $(F(3,313)=2.992, p=.031)$, respectively. The results of the Tukey test for ES, Persistent, and HS were according to the following order, namely, Year Four, Year One, Year Two, and Year Three, respectively. Besides, TM also significant difference $(F(3,311)=3.511, p=.016)$ in terms of years of study, where the Tukey test results were in the order of Year One, Year Four, Year Two, and Year Three, respectively. These results suggest that the years of study affect the SRLs of Arabic learners. The Year Four and Year One learners displayed higher levels of MS, ES, TM, Persistence, and HS, while Year Three learners had the lowest SRLs. Therefore, $\mathrm{H}_{2}$ was accepted.

Table 8

Tukey HSD

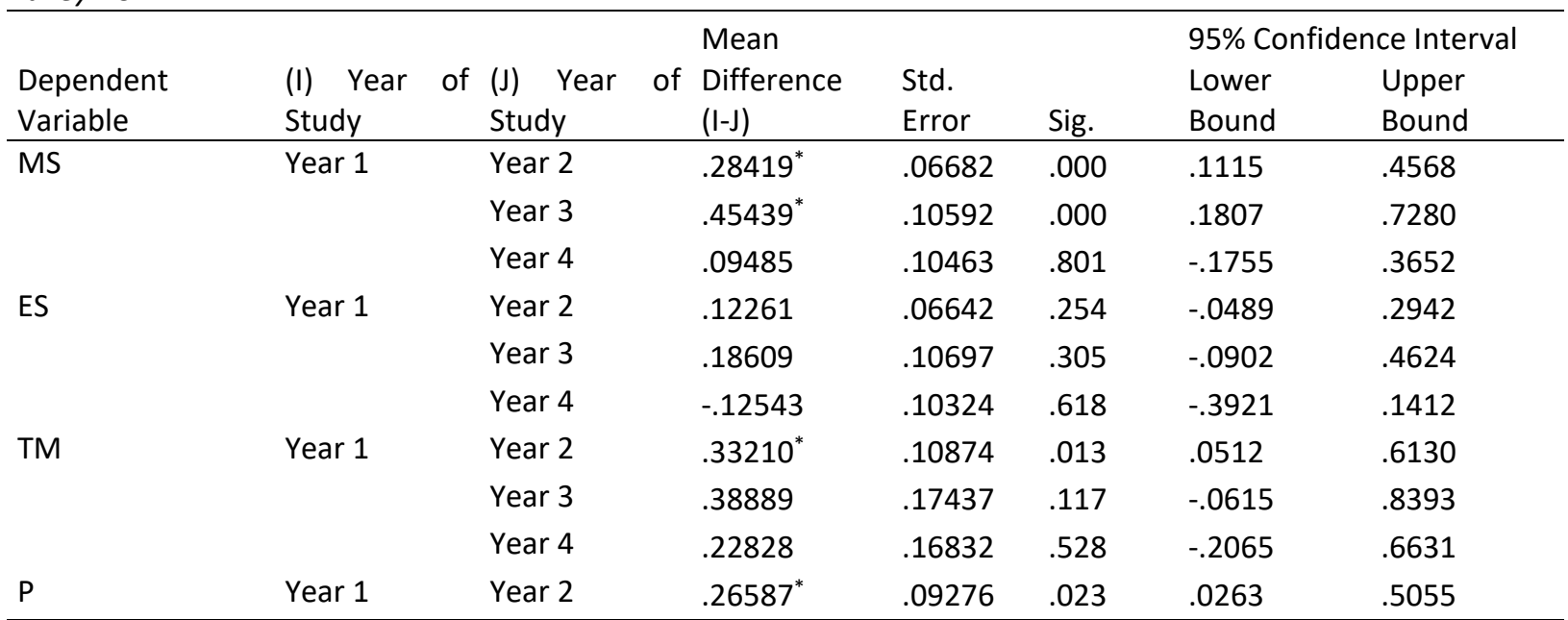




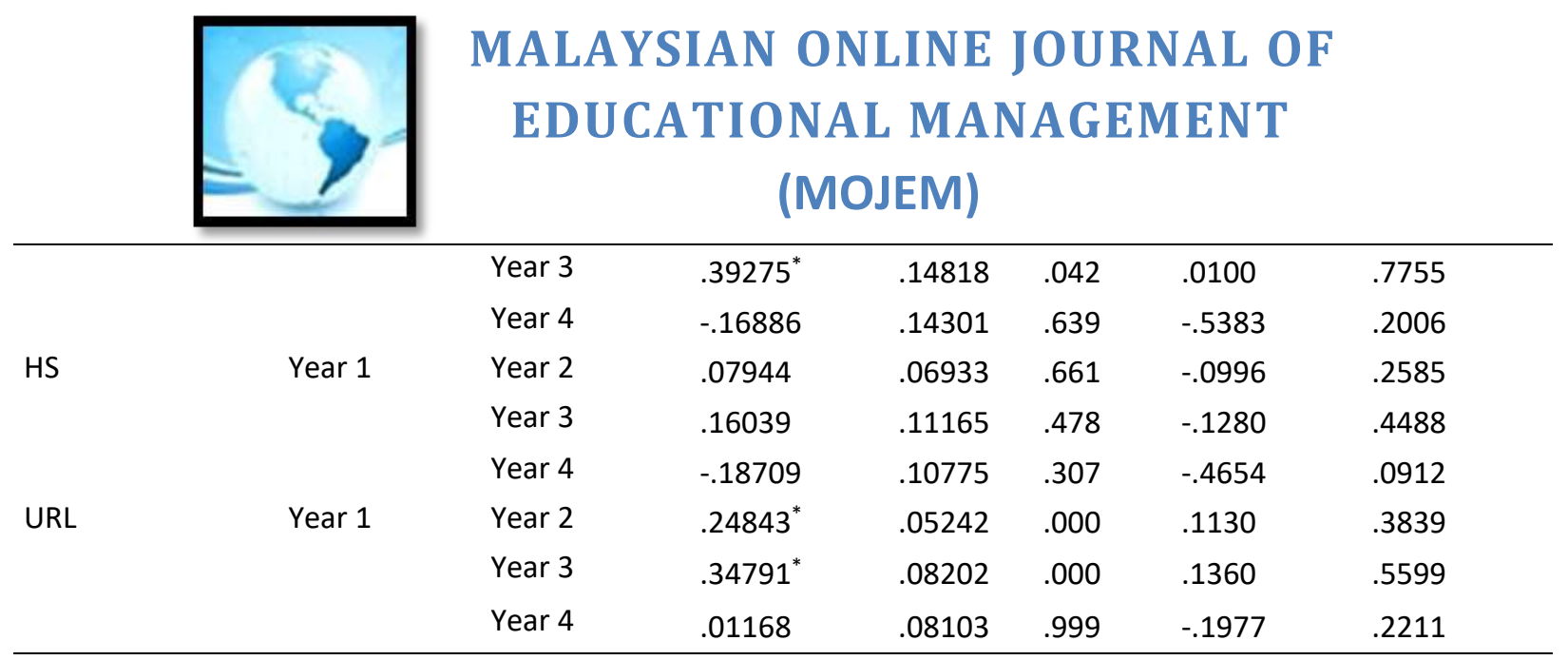

*. The mean difference is significant at the 0.05 level.

\section{Test of Hypotheses 3}

$\mathrm{H}_{3}$ : There are significant influences of self-regulated learning strategies in academic achievement.

$\mathrm{H}_{3 a}$ : There is a significant influence of MS in academic achievement.

$\mathrm{H}_{3 b}$ : There is a significant influence of ES in academic achievement.

$\mathrm{H}_{3 c}$ : There is a significant influence of Persistent in academic achievement.

$\mathrm{H}_{3 \mathrm{~d}}$ : There is a significant influence of TM in academic achievement

$\mathrm{H}_{3 e}$ : There is a significant influence of HS in academic achievement

\section{Regression Coefficients}

Table 9

Multiple Regression Analysis for independent variables and academic performance

\begin{tabular}{lllll}
\hline Model & $\mathrm{R}$ & $\mathrm{R}$ Square & Adjusted R Square & Std. Error of the Estimate \\
\hline 1 & $.231^{\mathrm{a}}$ & .053 & .037 & .57545 \\
\hline
\end{tabular}

a. Predictors: (Constant), MS, ES, TM, Persistence, HS

As displayed in Multiple Regression Analysis for independent variables (MS, ES, TM, Persistence, HS) and academic outcome, the $\mathrm{R}^{2}$ value, which is .053 , indicated that $5 \%$ of the change in academic achievement is caused by MS, ES, TM, Persistence, and HS, whereas the remaining $95 \%$ of change cannot be predicted as it may be caused by other variables which are not studied in this study.

Table 10

ANOVA Analysis of independent variables and academic performance

\begin{tabular}{lllllll}
\hline Model & & Sum of Squares & Df & Mean Square & $F$ & Sig. \\
\hline 1 & Regression & 5.416 & 5 & 1.083 & 3.271 & $.007 \mathrm{~b}$ \\
& Residual & 96.030 & 290 & .331 & & \\
& Total & 101.446 & 295 & & & \\
\hline
\end{tabular}

a. Dependent Variable: academic achievement

b. Predictors: (Constant), MS, ES, TM, Persistence, HS

The ANOVA table is used to examine the statistical significance of the result. Table 8 indicated that the model was statistically significant at $p<.05$. It indicated the linear relationship between independent variables and dependent variables in the model. Therefore, the model is well fit to predict the academic performance of MS, ES, TM, Persistence, and HS. In other words, MS, ES, TM, Persistence, and HS can be used reliable to predict academic achievement. 


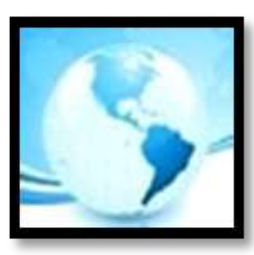

MALAYSIAN ONLINE JOURNAL OF

EDUCATIONAL MANAGEMENT

(MOJEM)

Table 11

Regression Coefficients between SRLs and Academic achievement

\begin{tabular}{|c|c|c|c|c|c|c|c|}
\hline & \multicolumn{2}{|c|}{$\begin{array}{l}\text { Unstandardized } \\
\text { Coefficients }\end{array}$} & \multirow{2}{*}{$\begin{array}{l}\text { Standardized } \\
\text { Coefficients } \\
\text { Beta }\end{array}$} & \multirow[b]{2}{*}{$t$} & \multirow[b]{2}{*}{ Sig. } & \multicolumn{2}{|c|}{ Collinearity Statistics } \\
\hline & $B$ & Std. Error & & & & Tolerance & VIF \\
\hline (Constant) & 2.228 & .323 & & 6.905 & .000 & & \\
\hline MS & .224 & .093 & .197 & 2.406 & .017 & .487 & 2.051 \\
\hline ES & -.023 & .082 & -.020 & -.284 & .776 & .657 & 1.521 \\
\hline TM & .056 & .042 & .080 & 1.313 & .190 & .874 & 1.144 \\
\hline Persistence & -.025 & .059 & -.030 & -.419 & .676 & .640 & 1.562 \\
\hline HS & .046 & .079 & .042 & .578 & .563 & .633 & 1.579 \\
\hline
\end{tabular}

By referring to Table 11, Metacognitive skills, environment structural, time management, Persistence, help-seeking were brought together in a single model as predictors for academic performance were computed. Liner Regression showed that $t$-statistics with values more than 1.96 for the individual path between Metacognitive skills and GPA $(\beta=.224, t=2.406, p<.05)$, which demonstrated that MS alone with significant influence in academic outcomes. However, Time management $(\beta=.56, t=1.313, p>.05)$; Environmental structuring $(\beta=-.023, t=-.284, p>.05)$; Persistence $(\beta=-.025, t=-.419, p>.05)$; and Help-seeking $(\beta=.046, t=.578, p>.05)$ are not statistically significant influence in academic achievement at the level of $p>.05$. According to Hair et al. (2011), the effect of Arabic learners' Metacognitive skills on academic achievement (GPA) is considered quite weak. Besides, Time management, Environmental structuring, Help-seeking, and Persistence strategies will not influence learners' academic outcomes. Hence, $\mathrm{H}_{3 a}$ was accepted, and $\mathrm{H}_{3 b}, \mathrm{H}_{3 c}, \mathrm{H}_{3 d}$, and $\mathrm{H}_{3 e}$ were rejected.

\section{DISCUSSION AND CONCLUSION}

The finding of this study revealed that Arabic learners to have a medium level of self-regulated learning, high level of help-seeking, medium level of metacognitive skills, persistence, environmental structuring, and low level of time management. In other words, Arabic learners more frequently use help-seeking strategies compared to MS, persistence, ES, and TM. So, the respondents seem to need improvement in MS, persistence, ES, and TM strategies. The finding also declared that SRL in total is not a significant influence in learning performance, and MS is the only dimension significantly influencing learning performance. That is, SRL is not a predictor of Arabic learners' academic outcomes, and this result is inconsistent with a considerable number of studies such as Ablard and Lipschultz (1998), Andrade and Bunker (2009); Seker (2016); Ibrahim et al. (2015); Zimmerman and MartinezPons (1986), but it was consistent with Mahmoodi et al., (2014). Furthermore, this study found no gender difference in self-regulated learning among Arabic learners. As a result, there is an urgent need to improve Arabic learners' SRL.

To improve students' SRL, Shanker (2016) proposed practical actions to foster students five domains model of selfregulation in the classroom, where applicable for parents, instructors, faculty management, and administrators. Besides, Shanker (2016) reported with more effort in remaining optimally regulated, it can help to improve the way we can help a student to achieve optimal regulation. In other words, teachers and parents who care for students need to pay attention to their self-regulation. Hence, it is assumed that the combination of Shanker (2016) Five domains model of self-regulation and "eight emerging trends in K-12 education" in the education system is to promote success among life-long learners in language learning, or in general. Yet, this assumption needs further verification from educators, researchers, faculty management and administrators.

On the other hand, it is worth mentioning the findings also presented the notion that the Malaysian Arabic learners lack time management skills. The time management problems among university students is a recurring one. Past studies (Lynch \& Dembo, 2004; Goldfinch \& Hughes, 2007; Van Den Hurk, 2006; Khanam et al., 2017) 


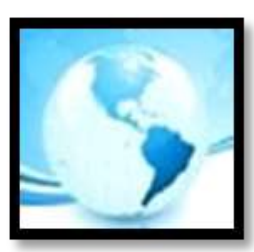

\section{MALAYSIAN ONLINE JOURNAL OF EDUCATIONAL MANAGEMENT (MOJEM)}

confirmed that time management is a contributing factor to students' achievement and withdrawal from a course in a variety of learning contexts. Macan, Shahani, Dipboye, and Phillips (1990) studied 165 college students' time management and revealed the most predictive factor was perceived control of time, which refers to the feeling that one is in control concerning how time at work is spent. For example, the learners do not know "What did I do today, where did my time go to?" Time management ability can be improved in some ways. First, the learner must set goals for their learning, such as completing a review of the first semester's assignment, completing a review of the first half of the second-semester assignment, complete the review problems or practice test that your professor distributed in class. Second, build time management according to importance and urgency. Many time management tools can be applied according to personal preference, such as time management app in smartphones including Create a To-Do List, The Weekly Planner, Google Calendar, Time Tracking, Remember Tips, Sticky Notes, TASK oriented or TIME orientated, and so on.

Besides, as displayed in finding part, $\mathrm{H}_{1}$ was rejected, and in turn, $\mathrm{H}_{2}$ was accepted. The present study indicated that the gender of the respondents did not play any role in the results of the SRLs. These results suggest that gender does not affect the MS, ES, TM, Persistent, and HS of Arabic learners. Consistently, this issue was similar to Yusri (2010) and Yusri, Rahimi, Shah, and Wah $(2011$; 2013) which found Arabic learners to have no gender difference in regards to SRLs. In contrast, the current finding also showed that MS, ES, TM, Persistent, and HS were significantly different between Year One, Year Two, Year Three and Year Four learners. The findings were consistent with Xuan et al. (2020) and inconsistent with Yusri (2010) and Yusri et al. (2011, 2013). Interestingly, Year One and Year Four learners had high levels of MS, ES, TM, Persistent, and HS, and Year Three and Year Two learners had lower levels than the others. All these results have presented an implication for policy implementation and research studies in the future. One such implication showed that these outcomes were required for investigating why the Year 2 and 3 students showed a low academic self-management level, and how these levels could be improved.

One of the strong points of this study is its attempt to predict academic performance based on a similar set of predictors in a similar context. This allows for some comparisons across outcome variables and provide some preliminary hypotheses for further research. The regression coefficients convincingly demonstrated that $\mathrm{H}_{3 a}$ was accepted, yet, $\mathrm{H}_{3 b}, \mathrm{H}_{3 c}, \mathrm{H}_{3 e}$, and $\mathrm{H}_{3 d}$ were rejected. In other words, MS was a strategy that significantly predicts in Arabic learners' academic achievement only. The finding was similar to (Nosratinia, Saveiy, \& Zaker, 2014; Anderson, 2003; Kartal, 2013). In turn, ES, TM, HS, and Persistent were not significantly influence in learners' academic outcomes. These findings were consistent with (Wahat, Saat, Ching, Qin, May, Omar... \& Omar, 2012; Taplin, Yum, Jegede, Fan, \& Chan, 2001; Williams \& Takaku, 2011; Villavicencio, 2011). The opposite of the findings are researches by (Kosnin, 2007; Abbasnasab, 2012; Ibrahim et al., 2015; Seker, 2016; Haron et al., 2010).

Results of this study may not only advance the current insights in the relationship between academic selfmanagement skills and performance, but it may also provide some suggestions for universities, faculties, and related departments in terms of the design of coaching programs or activities for language learning students. This study also provides some implications for the Ministry of Education (MOE) Malaysia, practitioners including Arabic language department policymakers in universities, researchers, teachers, students, and parents. Based on the finding of this study, the Ministry and higher education institutes may identify new teaching and learning strategies for both course instructors and students. Moreover, the findings indicate that a medium degree of mean in Arabic learners' SRLs, SMU, and high level of mean in motivation in Arabic language learning. This may affect the Arabic language department policymakers in university, teachers, students, and parents, in their effort to improve learners' SRLs in Arabic learning, and consequently increase the strategies usage in Arabic learning. Therefore, this study was able to provide empirical evidence for the language department policymakers or university administrators to comprehend and create fitting strategies and policies to both maintain and increase the level of learners' Arabic language performance. Besides, it essential to foster the self-regulated learning of our students and enable them to "learn to learn." The Ministry of Education (MOE) Malaysia may refer to the findings of the current study to add or modify the strategies and motivational variables in terms of Arabic language learning. For 


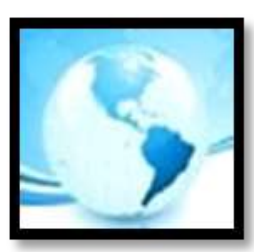

\section{MALAYSIAN ONLINE JOURNAL OF EDUCATIONAL MANAGEMENT (MOJEM)}

example, based on the findings, Arabic language learners are very weak in time management strategies use. The language pedagogy department of the Ministry of Education (MOE) can use this information to provide universities with guidance on how to improve the Arabic language learning, for example by creating specific plans for developing learners' time management strategies such as by organizing workshops and introducing time management tools and apps. As Kadiyono and Hafiar (2017) reported in their study "If the priority is helping students pass course-modules, the focus should not solely be on motivating students, but also supporting them in acquiring regulatory skills".

In conclusion, facilitating self-regulated learning factors should be used on an individual basis to reduce the effect of inhibiting factors in improving self-regulation among students (Jouhari, Haghani, \& Changiz, 2015). Thus, what the learners need to do is find the strategies that fit their learning process. As mentioned by Oxford (2011), the foreign language learners develop their learning strategies according to personality, biography, and situational factors. Nowadays, the purpose of education is not limited to developing students' hard power, such as Education background, Language ability, Professional skills only, but it is about combining hard power and soft powers, for instance, attitude, experience, empathy, honesty to foster 21st-century skills students. Lastly, the researchers assumed that SRLs assist in combining students' Hard and Soft powers, and future studies can further investigate in terms of this aspect.

\section{REFERENCES}

Abbasnasab, S. (2012). Self-regulated learning strategies (SRLS) and academic achievement in pre-university EFL learners. California Linguistic Notes, 37(1), 1-35.

Ablard, K. E., \& Lipschultz, R. E. (1998). Self-regulated learning in high-achieving students: Relations to advanced reasoning, achievement goals, and gender. Journal of Educational Psychology, 90(1), 94-101.

Adams, R. V., \& Blair, E. (2019). Impact of time management behaviors on undergraduate engineering students' performance. SAGE Open, 9(1), 1 - 11.

Anderson, N. J. (2003). Metacognitive reading strategies increase L2 performance. The Language Teacher, 27(7), 20-22.

Andrade, M. S., \& Bunker, E. L. (2009). A model for self-regulated distance language learning. Distance Education, 30(1), 47-61.

Black, S., \& Allen, J. D. (2019). Part 8: Academic help-seeking. The Reference Librarian, 60(1), 62-76. https://doi.org/10.1080/02763877.2018.1533910

Brown, A. L. (1987). Metacognition, executive control, self-regulation, and other more mysterious mechanisms. In F. E. Weinert, \& R. H. Kluwe (Eds.), Metacognition, motivation, and understanding (pp. 65-116). Hillsdale, New Jersey: Lawrence Erlbaum Associates.

Chua, Y. P. (2013). Mastering research statistics. Shah Alam, Malaysia : McGraw-Hill Education.

Dabbagh, N., \& Kitsantas, A. (2012). Personal learning environments, social media, and self-regulated learning: A natural formula for connecting formal and informal learning. The Internet and Higher Education, 15(1), 3-8.

Drucker, P. F. (2005). Managing oneself. Harvard Business Review, 83(1), 100-109.

Duncan, T. G., \& McKeachie, W. J. (2005). The making of the motivated strategies for learning questionnaire. Educational psychologist, 40(2), 117-128. Fitzgibbon, K., \& Prior, J. (2003, April). Student expectations and university interventions-a timeline to aid undergraduate student retention. In BEST Conference: Creativity and Innovation in Academic Practice, Brighton, 9-11 April 2003.

Flavell, J. H. (1979). Metacognition and cognitive monitoring: A new area of cognitive-developmental inquiry. American Psychologist, 34(10), 906 - 911.

Forgas, J. P., Baumeister, R. F., \& Tice, D. M. (2011). Psychology of self-regulation: Cognitive, affective, and motivational processes. US: Psychology Press.

Ganguly, S., Kulkarni, M., \& Gupta, M. (2017). A self-efficacy intervention for poorly performing students. Indian Journal of Psychology and Education, 7(2), 63-66. 


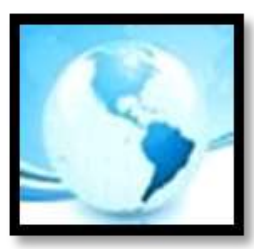

\section{MALAYSIAN ONLINE JOURNAL OF EDUCATIONAL MANAGEMENT (MOJEM)}

Garavalia, L. S., Scheuer, D. A., \& Carroll, C. A. (2002). Comparative analysis of first-and third-year pharmacy students' perceptions of student-regulated learning strategies and motivation. American Journal of Pharmaceutical Education, 66(3), 219-222.

Goldfinch, J., \& Hughes, M. (2007). Skills, learning styles and success of first-year undergraduates. Active Learning in Higher Education, 8(3), 259-273.

Google \& Canvas8. (2019). Future of the classroom: Emerging trends in K-12 education. Global Edition. Retrieved from http://hdl.voced.edu.au/10707/525927.

Gravill, J., \& Compeau, D. (2008). Self-regulated learning strategies and software training. Information \& Management, 45(5), 288-296.

Hair, J. F., Ringle, C. M., \& Sarstedt, M. (2011). PLS-SEM: Indeed a silver bullet. Journal of Marketing Theory and Practice, 19(2), 139-152.

Haron, S. C., Ahmad, I. S., Mamat, A., \& Mohamed, I. H. A. (2010). Understanding Arabic-speaking skill learning strategies among selected Malay learners: A case-study at the International Islamic University Malaysia (IIUM). Contemporary Issues in Education Research, 3(8), 9-20.

Ibrahim, E. E. M., Jani, M., Alias, A., Yasin, F., Firdaus, R., \& Zakariyah, L. (2015). Interaction with the Qur'an and self-regulated learning vis-à-vis academic achievement of undergraduate students. The International Journal of Current Research and Academic Review, 3(9), 189-197.

Jansen, R. S., Van Leeuwen, A., Janssen, J., Kester, L., \& Kalz, M. (2017). Validation of the self-regulated online learning questionnaire. Journal of Computing in Higher Education, 29(1), 6-27.

Jouhari, Z., Haghani, F., \& Changiz, T. (2015). Factors affecting self-regulated learning in medical students: a qualitative study. Medical Education Online, 20(1), 28694.

Karabenick, S. A., \& Berger, J.-L. (2013). Help seeking as a self-regulated learning strategy. In H. Bembenutty, T. J. Cleary, \& A. Kitsantas (Eds.), Applications of self-regulated learning across diverse disciplines: $A$ tribute to Barry J. Zimmerman (p. 237-261). IAP Information Age Publishing.

Karabenick, S. A., \& Dembo, M. H. (2011). Understanding and facilitating self-regulated help seeking. New Directions for Teaching and Learning, 126, 33-43. https://doi.org/10.1002/tl.442

Karabenick, S. A. (2004). Perceived achievement goal structure and college student help seeking. Journal of Educational Psychology, 96(3), 569-581. https://doi.org/10.1037/0022-0663.96.3.569

Kadiyono, A., \& Hafiar, H. (2017). The role of academic self-management in improving students' academic achievement. doi:10.1201/9781315166575-30

Kartal, G. (2013). The effect of cognitive and metacognitive strategies on self-efficacy beliefs of freshman EFL students. In International Conference "ICT for Language Learning" (pp. 1-5).

Khanam, N., Sahu, T., Rao, E. V., Kar, S. K., \& Quazi, S. Z. (2017). A study on university student's time management and academic achievement. International Journal of Community Medicine and Public Health, 4(12), 47614765.

King-Sears, M. (2006). Self-management for students with disabilities: The importance of teacher follow-up. International Journal of Special Education, 21(2), 94-108.

Kosnin, A. M. (2007). Self-regulated learning and academic achievement in Malaysian undergraduates. International Education Journal, 8(1), 221-228.

Lynch, R., \& Dembo, M. (2004). The relationship between self-regulation and online learning in a blended learning context. The International Review of Research in Open and Distributed Learning, 5(2), 1 - 16.

Macan, T. H., Shahani, C., Dipboye, R. L., \& Phillips, A. P. (1990). College students' time management: Correlations with academic performance and stress. Journal of Educational Psychology, 82(4), 760-768.

Mahmoodi, M. H., Kalantari, B., \& Ghaslani, R. (2014). Self-regulated learning (SRL), motivation, and language achievement of Iranian EFL learners. Procedia-Social and Behavioral Sciences, 98, 1062-1068.

Matzat, U., \& Vrieling, E. (2016). Self-regulated learning and social media-a 'natural alliance'? Evidence on students' self-regulation of learning, social media use, and student-teacher relationship. Learning, Media and Technology, 41(1), 73-99. 


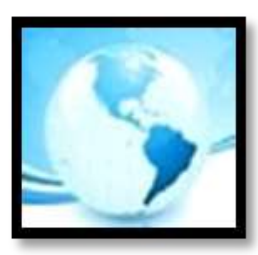

MALAYSIAN ONLINE JOURNAL OF

EDUCATIONAL MANAGEMENT

(MOJEM)

Newman, R. S. (2000). Social influences on the development of children's adaptive help seeking: The role of parents, teachers, and peers. Developmental Review, 20(3), 350-404. https://doi.org/10.1006/drev.1999.0502

Nosratinia, M., Saveiy, M., \& Zaker, A. (2014). EFL learners' self-efficacy, metacognitive awareness, and use of language learning strategies: How are they associated? Theory and Practice in Language Studies, 4(5), 10801092.

Oxford, R. L. (1999). Relationships between second language learning strategies and language proficiency in the context of learner autonomy and self-regulation. Revista Canaria de Estudios Ingleses, 38, 109-126.

Oxford, R. L. (2011). Strategies for learning a second or foreign language. Language Teaching, 44(2), $167-180$.

Pintrich, P. R. (1991). A manual for the use of the Motivated Strategies for Learning Questionnaire (MSLQ). Retrieved from https://eric.ed.gov/?id=ED338122.

Pintrich, P. R. (1995). Understanding self-regulated learning. New Directions for Teaching and Learning, 63, 3-12.

Pintrich, P. R. (2004). A conceptual framework for assessing motivation and self-regulated learning in college students. Educational Psychology Review, 16(4), 385-407.

Pozdeeva, E. S. (2019). Studentstime management in higher education: review of the literature. Hayкa $u$ человечество, 1(1), 65-99.

Ryan, A. M., Pintrich, P. R., \& Midgley, C. (2001). Avoiding seeking help in the classroom: Who and Why? Educational Psychology Review, 13, 93-114. https://doi.org/10.1023/A:1009013420053

Samani, S. A., \& Samani, S. A. (2012). The impact of indoor lighting on students' learning performance in learning environments: A knowledge internalization perspective. International Journal of Business and Social Science, 3(24), $127-136$.

Seker, M. (2016). The use of self-regulation strategies by foreign language learners and their role in language achievement. Language Teaching Research, 20(5), 600-618.

Shanker, S. (2016). Self-reg: How to help your child (and you) break the stress cycle and successfully engage with life. London, UK: Penguin Press.

Schraw, G., \& Dennison, R. S. (1994). Assessing metacognitive awareness. Contemporary Educational Psychology, 19(4), 460-475.

Taplin, M., Yum, J. C., Jegede, O., Fan, R. Y., \& Chan, M. S. C. (2001). Help-seeking strategies used by high-achieving and low-achieving distance education students. Journal of Distance Education, 16(1), 56-69.

Tinto, V. (2017). Reflections on student persistence. Student Success, 8(2), 1-9.

Tu, C.-H., Yen, C.-J., \& Sujo-Montes, L. E. (2015). Personal learning environments and self-regulated learning. In R. Papa (Ed.), Media-rich instruction: Connecting curriculum to all learners (pp. 35-48). New York: Springer.

Van Den Hurk, M. (2006). The relation between self-regulated strategies and individual study time, prepared participation and achievement in a problem-based curriculum. Active Learning in Higher Education, 7(2), 155-169.

Villavicencio, F. T. (2011). Influence of self-efficacy and help-seeking on task value and academic achievement. Philippine Journal of psychology, 44(2), 166-180.

Wahat, N. H. A., Saat, N. Z. M., Ching, C. K., Qin, L. Y., May, G. C., Omar, N., ... \& Omar, S. S. (2012). Time management skill and stress level among audiology and speech sciences students of Universiti Kebangsaan Malaysia. Procedia-Social and Behavioral Sciences, 59, 704-708.

Warr, P., \& Downing, J. (2000). Learning strategies, learning anxiety and knowledge acquisition. British Journal of Psychology, 91(3), 311-333.

Williams, J. D., \& Takaku, S. (2011). Help seeking, self-efficacy, and writing performance among college students. Journal of Writing Research, 3(1), 1-18. doi: 10.17239/jowr-2011.03.01.1

Xuan, D., Azhar Zailani, M., \& Muin Ismail, W. (2020). The influence of self-efficacy, task value, and goal orientation on help-seeking and academic performance. Humanities \& Social Sciences Reviews, 8(2), $722-731$. https://doi.org/10.18510/hssr.2020.8281

Yusri, G. (2010). Self-regulated learning strategies among students of Arabic language course and intensive Arabic course in Mara University of Technology Malaysia (UITM). International Journal of Applied Educational Studies, 8(1), 57. 


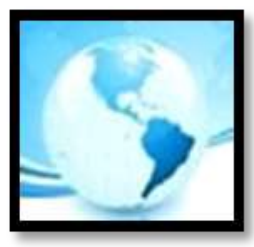

\section{MALAYSIAN ONLINE JOURNAL OF EDUCATIONAL MANAGEMENT (MOJEM)}

Yusri, G., Rahimi, N. M., Shah, P. M., \& Wah, W. H. (2013). Cognitive and metacognitive learning strategies among Arabic language students. Interactive Learning Environments, 21(3), 290-300.

Yusri, G., Rahimi, N. M., \& Wah, W. H. (2011). Value and resource management strategies among students of Arabic as a third language course. Procedia-Social and Behavioral Sciences, 29, 1635-1644.

Zimmerman, B. J., \& Campillo, M. (2003). Motivating self-regulated problem-solvers. In J. E. Davidson \& R. J. Sternberg (Eds.), The psychology of problem-solving (pp. 233-262). New York, NY: Cambridge University Press.

Zimmerman, B. J., Greenberg, D., \& Weinstein, C. E. (1994). Self-regulating academic study time: A strategic approach. In D. H. Schunk \& B. J. Zimmerman (Eds.), Self-regulation of learning and performance: Issues and educational applications (pp. 181-199). Mahwah, NJ: Erlbaum.

Zimmerman, B. J., \& Martinez-Pons, M. (1986). Development of a structured interview for assessing student use of self-regulated learning strategies. American Educational Research Journal, 23(4), 614-628.

Zimmerman, B. J., \& Martinez-Pons, M. (1988). Construct validation of a strategy model of student self-regulated learning. Journal of Educational Psychology, 80(3), 284-290. 